\title{
Speaking up for balance: analysis of the gender of invited speakers at UK dental conferences
}

\author{
Claudia Heggie, ${ }^{* 1}$ Sarah L. McKernon² and Laura Gartshore ${ }^{3}$
}

\section{Key points}

Allows readers to consider gender equity at dental conferences.

Considers how gender impacts dental training career progression and choice of specialism.
Allows readers who are members of conference organising committees to consider gender equity at dental conferences going forwards.

\begin{abstract}
Introduction Across healthcare, there is an urgent call to action to address systematic gender bias impeding equity for women. Gender imbalance exists for speakers at medical conferences. This research presents the first descriptive analysis of gender balance of speakers at dental conferences.

Objectives Describe the gender balance of invited speakers at UK conferences of the dental specialties and general dentistry in a two-year period. Consider the findings in relation to gender balance of dental and specialist registrants.

Method Gender, presentation length and professional role were extracted from conference programmes. Acceptable gender balance was pre-specified as 40-60\%. Gender data were extracted from the GDC registration report.

Results Of 352 invited speakers, 39.8\% ( $n=140)$ were identified as female and $60.2 \%(n=212)$ as male. Gender was acceptably balanced in $21.4 \%(n=3)$ of conferences. Gender balance of specialist speakers varied, as does gender distribution within the specialties themselves. Only 38.5\% $(n=5)$ of specialties had a specialist speaker gender balance representative of their speciality.

Conclusion There is a call for further research to drive equity in the characteristics of invited speakers and to determine whether there is correlation with representation in the composition of conference organising committees, leadership, professional roles and the workforce. Conference organisers are encouraged to strive proactively and prospectively towards representative programmes.
\end{abstract}

\section{Background}

Gender refers to the socially constructed identities of male, female and gender-diverse people. The World Health Organisation (WHO) defines gender as the roles, behaviours, activities, attributes and opportunities that any society considers appropriate for girls and boys, and women and men. ${ }^{1}$ Gender influences self-perception, perception of others, social interaction and the distribution of power in our society. The WHO advises

${ }^{1}$ Academic Clinical Fellow and Specialty Trainee in Paediatric Dentistry, University of Leeds; ${ }^{2}$ Clinical Lecturer and Specialist in Oral Surgery, School of Dentistry, University of Liverpool, UK; ${ }^{3}$ Senior Lecturer and Honorary Consultant in Paediatric Dentistry, School of Dentistry,

University of Liverpool, UK

*Correspondence to: Claudia Heggie

Email address: Claudia.heggie@nhs.net

Refereed Paper

Accepted 11 September 2020

https://doi.org/10.1038/s41415-021-3072-2 that gender has implications throughout the life course for both women and men, while intersecting with a multitude of factors that drive inequalities including: ethnicity, socioeconomic status, disability, age and sexual orientation, among others. Gender equality and women's empowerment can improve health; the WHO strives to challenge gender stereotypes and combat gender inequality to ensure health equity. Gender identity describes an individual's personal sense about their gender and how they wish to be known by others. Gender identity can correlate with assigned sex at birth or can differ from it. Gender expression typically reflects a person's gender identity, but this is not always the case. A spectrum of gender identities and gender expressions exist. ${ }^{2,3,4}$

Globally, women comprise $70 \%$ of the health and social care workforce, with a welldocumented gender pay gap., ${ }^{5,6}$ In the UK in 2014 , only $44 \%$ of the 267,300 registered doctors were female, yet $55 \%$ of medical undergraduates were female. ${ }^{7}$ According to UCAS, in $2016,58 \%$ of people accepted on to medicine and dentistry courses in the UK were female. In the same year, women made up $11.1 \%$ of consultant surgeons in England. The increased proportion of female undergraduate students does not yet appear to be translating through into a similarly increased proportion of female surgeons; however, there appears to be a positive trend developing (Fig. 1). If this trend continues, it is predicted that a majority of the UK healthcare workforce will be female within the next ten years. Despite the apparently balancing trends, women continue to be under-represented in medical leadership and academic roles. ${ }^{8}$ Only $24 \%$ of trust medical directors are female and only $37 \%$ of all senior roles are held by women. ${ }^{9} \mathrm{~A}$ number of barriers to women progressing to leadership roles have been identified including personal expectations, organisational cultures 
and work-life balance, which may have a cumulative effect on progression (Figures 2 and 3)..$^{7,10}$

It appears that within the NHS, there persists to be reported unconscious bias and, more rarely, active discrimination against women. ${ }^{11}$ Such gender inequalities may also be problematic for men in traditionally femaledominated professions, such as dental care professional roles, where they may experience discrimination in recruitment. However, men within these non-traditional roles are assumed to adopt leadership positions. ${ }^{12,13}$ Furthermore, there is an enduring gender pay gap in the NHS of $23 \%$ in favour of men based on total pay, or $17 \%$ when considering only the salary of doctors. $^{14}$

Initiatives such as Women in Surgery (WinS), hosted by the Royal College of Surgeons of England (RCS), are dedicated to encouraging, enabling and inspiring women to fulfil their career ambitions and to address the gender balance. ${ }^{15}$ Similarly, opportunities are emerging, such as the Lady Estelle Wolfson Emerging Leaders Fellowship (LEWELF), to encourage women to apply for senior and leadership roles in the RCS and in surgery. ${ }^{16}$ The Emerging Leaders Fellowship was born of recognition that women may experience imposter syndrome, fear of the unknown and have responsibilities that may discourage them from applying to leadership roles. Applications of dental members of the RCS are welcomed to both WinS and the LEWELF.

In line with the call for action to address diversity and inclusivity across healthcare, our professions are tasked with striving for gender balance in the workforce and also with respect to the invited conference speakers who represent and address that workforce. Healthcare conferences provide an opportunity to disseminate leading research and to showcase diversity and inclusivity within specialties. ${ }^{17}$ Furthermore, conference speakers may provide role modelling and mentorship opportunities to inspire career advancement. ${ }^{18}$ There may be opportunity to improve the gender balance of the conference panel if invited session chairs and panel members are also considered. ${ }^{19}$

There is extensive research to support that a gender imbalance exists for speakers invited to present at conferences in medicine; however, there is some suggestion that the situation appears to be improving. ${ }^{19,20,21,22,23}$ Where present, it is possible that gender imbalance of invited conference speakers reflects a disparity
Fig. 1 Gender balance of consultant female surgeons is improving, reproduced with permission from Royal College of Surgeons of England (data from NHS Digital)

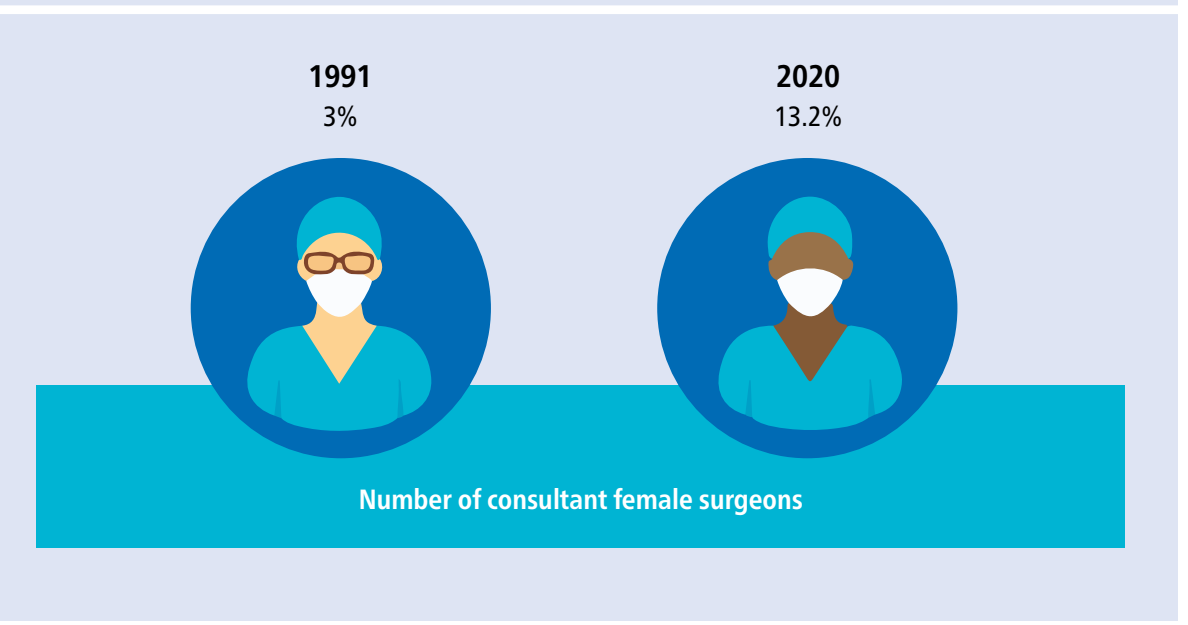

Fig. 2 Gender balance of registered doctors in the UK, permission to share granted by The King's Fund; originals available at: https://www.kingsfund.org.uk/audio-video/ women-and-medical-leadership-infographics

Of the 267,300 registered doctors in the UK, $44 \%$ are women

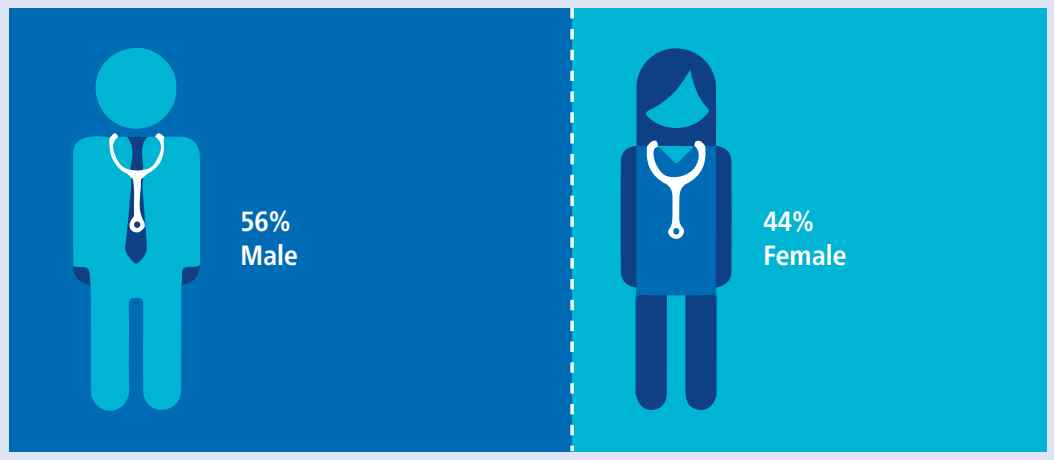

Registered doctors in the UK

Fig. 3 Gender imbalance in leadership may negatively impact organisational performance, permission to share granted by The King's Fund; originals available at: https://www. kingsfund.org.uk/audio-video/women-and-medical-leadership-infographics

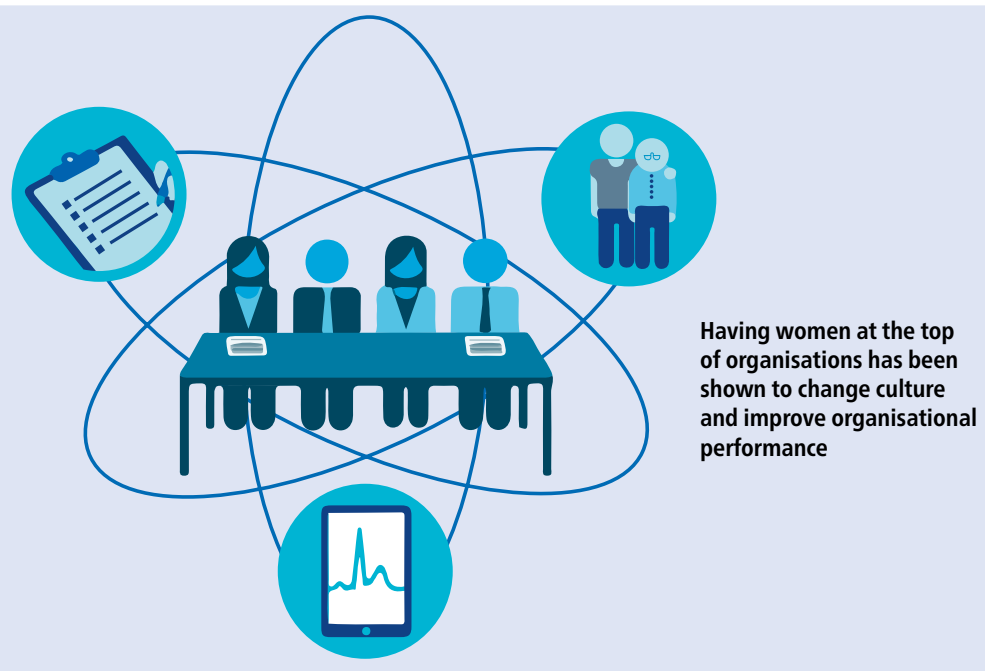


Fig. 4 The proportion of female consultants in surgical specialties remains low but is varied, reproduced with permission from Royal College of Surgeons of England (data from NHS Digital)

Percentage of consultants who are female within the following specialties:

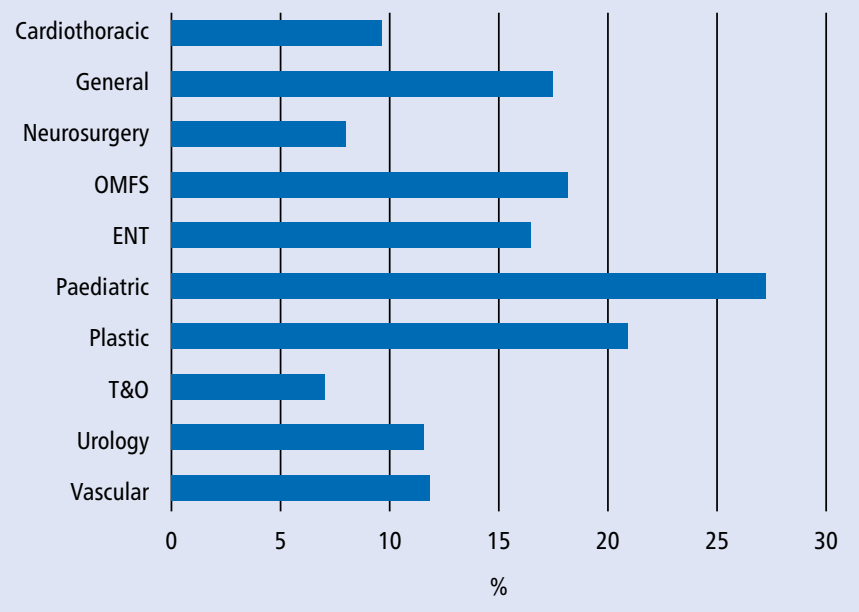

within specialties where women remain underrepresented in the workforce (Fig. 4)..$^{24,25}$ The balance of characteristics of conference organising committees in dentistry may or may not impact speaker characteristics; however, when women are involved in conference organising committees of medicine, the gender balance of speakers improves. ${ }^{20,26,27,28}$

In 2019, The Lancet made an urgent call to action to create institutional change to address concerns about systematic gender bias impeding the advancement of, and equity for, women within the fields of science, medicine and global health. They called this call to action 'feminism is for everybody. ${ }^{29}$ Six months later, they announced a new Diversity Pledge and No All-Male Panel Policy as part of the Lancet Group's commitment to increasing gender equity, diversity and inclusion in research and publishing. ${ }^{30}$ This call for action has been reiterated in dentistry, with a plea made to the British Dental Association (BDA) to show leadership and be the vanguard in promoting equality, inclusion and representation for women. ${ }^{31}$

In further recognition of the imbalance that persists, social media databases have been established to support the availability of female conference speakers and to raise awareness of the role of conference organisers in supporting gender balance. Examples include Twitter’s@ womenspeakersHC and @ManelWatchAU. It is noted that there is an army of supportive male allies for these initiatives who also wish to address the balance and that there are areas of healthcare in which men, too, are under-represented.
Within healthcare and gender-related research, gender data often relies on selfreporting. ${ }^{14}$ Alternatively, gender may be assumed by use of information in the public domain or use of gender-determining algorithms such as the Gender Bias Assessment Tool (GBAT). ${ }^{20,28}$ Positive initiatives for women in healthcare, such as annual gender pay gap reporting, rely on self-reporting and do not make reference to people identifying beyond the binary. ${ }^{32}$

The primary objective of this research was to provide a descriptive analysis of the gender balance of invited speakers at conferences of general and specialist dentistry in the UK in 2018 and 2019. The secondary objective was to consider this data in relation to the gender balance of registered specialists in each speciality and for all registered dentists. This is the first reported study of its kind in dentistry.

\section{Method}

National conference programmes were requested, by a Freedom of Information request, from the 13 dental speciality societies and the BDA for the years 2018 and 2019. Where this information was not provided, the public domain was searched for programme information.

The BDA was included as a widely recognised representative of general dentistry. It is acknowledged that other conferences of primary care occur; however, for consistency with one conference per speciality, the BDA conference was selected given that it is synonymous with general dentistry in the
UK. In 2018 and 2019, the BDA hosted a 'theatre' at the Dentistry Show rather than hosting a full conference. All other theatres at the Dentistry Show were excluded from analysis as these were often subspeciality and it is acknowledged that speakers at these theatres may contribute financially for this opportunity. The same parameters were applied to speciality conferences but were found to be not applicable.

\section{Primary objective data extraction}

The following data were extracted for all main conference invited speakers, where available:

- Gender

- Length of presentation

- Professional role

- Gender of panel members and session chairs.

To infer binary gender, the use of pronouns where available, knowledge of speakers known to the authors or their colleagues and searching of the public domain were employed to identify gender as best as practically possible. For the purposes of analysis, it was agreed that a precise gender balance of 50:50 women-tomen would not allow reasonable and practical flexibility, or any room for consideration of the gender differences observed in the dental specialties. In contrast, a 70:30 split was agreed to represent imbalance. Gender balance was, therefore, pre-specified as acceptably balanced at $40-60 \%$ female speakers.

On occasions where two speakers were listed for one shared presentation, the duration was divided evenly between speakers. When one speaker presented multiple times at the same conference, each individual presentation listed was included in the analysis. When conferences were held biennially in a speciality, data were analysed for the most recent two events. When conferences were held on a biannual basis, the larger of the two events was analysed for each year. Where available, the gender of session chairs and panel members was also noted, given the opportunity to increase representation through these roles.

Professional role was extracted to identify speakers who appeared on specialist lists, in order to enable comparison of invited specialist speakers with gender balance of the dental specialties. Data were not extracted for non-invited speakers, such as those speaking in prize categories, at lunch and learn sessions, pre-congress teaching days or at subspeciality sessions such as those held by special interest groups and committee meetings. 


\section{Secondary objective data analysis}

The General Dental Council (GDC) registrant report for 2020 was supplied on request by the GDC. ${ }^{33}$ Registrants self-disclose gender and are asked if their gender identity is the same as the gender they were assigned at birth. The registrant report was reviewed to establish gender distribution:

- For all registered dentists

- Within each dental speciality.

In total, $50.4 \%(n=21,003)$ of registered dentists in the UK identified as female and $49.6 \%(n=20,667)$ as male, representing an almost equal gender balance. No registered dentists were recorded as having an undisclosed gender. There was variation in the proportion of women registered within each dental speciality (range 25.8\% [ $n=80]$ in endodontics to $78.9 \%$ [ $\mathrm{n}=191]$ in paediatric dentistry) (Table 1 ).

The GDC register was searched for the names of all speakers in order to analyse gender balance of speakers in relation to the gender balance of all registered dentists and of GDC-registered specialist dentists. Gender balance was, again, pre-specified as acceptably balanced at $40-60 \%$ female speakers.

\section{Results}

Complete conference programme data for the two-year period were obtained for $76.9 \%$ $(\mathrm{n}=10)$ of specialist societies and from the BDA. A partial dataset was obtained from the public domain for $23.1 \%(\mathrm{n}=3)$ of specialist societies. No programmes could be located for the British Society of Restorative Dentistry. However, conference programmes of the Specialty Registrars in Restorative Dentistry Group were included in lieu, following discussion with members of the speciality who advised their suitability for representation of restorative dentistry. Notably, one of the conferences of this group was jointly held with the British Society of Restorative Dentistry in 2019.

The speciality of oral microbiology convenes a biennial conference; therefore, the two most recent programmes were considered (2016 and 2018). For the speciality of oral medicine, a one-day programme for 2018 was available; however, this was not comparable to the twoday annual scientific meeting programme of 2018 which was unavailable. The one-day programme was excluded from analysis. No conference programme was available for the speciality of endodontics in 2018 .

Table 1 The gender of specialist dentists (of any speciality and for the relevant domain speciality) presenting at each conference domain compared with the gender balance of dentists registered as specialists in each speciality as per the GDC registrant report. Gender was acceptably balanced to pre-specified criteria of $40-60 \%$ female speakers. Gender balance of relevant domains' speciality speakers was within $10 \%$ variance of the gender balance of the speciality

\begin{tabular}{|c|c|c|c|c|c|c|}
\hline \multirow[b]{2}{*}{$\begin{array}{l}\text { Conference } \\
\text { domain }\end{array}$} & \multicolumn{3}{|c|}{ Male } & \multicolumn{3}{|c|}{ Female } \\
\hline & $\begin{array}{l}\text { Specialist } \\
\text { dentists as } \\
\text { speakers }\end{array}$ & $\begin{array}{l}\text { Specialist } \\
\text { dentists } \\
\text { from } \\
\text { relevant } \\
\text { speciality } \\
\text { as speakers }\end{array}$ & $\begin{array}{l}\text { Specialist } \\
\text { registrants }\end{array}$ & $\begin{array}{l}\text { Specialist } \\
\text { dentists as } \\
\text { speakers }\end{array}$ & $\begin{array}{l}\text { Specialist } \\
\text { dentists } \\
\text { from } \\
\text { relevant } \\
\text { speciality as } \\
\text { speakers }\end{array}$ & $\begin{array}{l}\text { Specialist } \\
\text { registrants }\end{array}$ \\
\hline $\begin{array}{l}\text { Dental and } \\
\text { maxillofacial } \\
\text { radiology }\end{array}$ & $\begin{array}{l}50.0 \% \\
(n=2)\end{array}$ & $0.0 \%(n=0)$ & $\begin{array}{l}46.4 \% \\
(n=13)\end{array}$ & $\begin{array}{l}50.0 \% \\
(n=2)^{\star *}\end{array}$ & $100.0 \%(n=1)$ & $\begin{array}{l}53.6 \% \\
(n=15)\end{array}$ \\
\hline $\begin{array}{l}\text { Dental public } \\
\text { health }\end{array}$ & $\begin{array}{l}40.0 \% \\
(n=2)\end{array}$ & $\begin{array}{l}25.0 \% \\
(n=1)\end{array}$ & $\begin{array}{l}42.9 \% \\
(n=42)\end{array}$ & $\begin{array}{l}60.0 \% \\
(n=3)^{* *}\end{array}$ & $75.0 \%(n=3)$ & $\begin{array}{l}57.1 \% \\
(n=56)\end{array}$ \\
\hline Endodontics* & $\begin{array}{l}100.0 \% \\
(n=1)\end{array}$ & $\begin{array}{l}100.0 \% \\
(n=1)\end{array}$ & $\begin{array}{l}74.2 \% \\
(n=230)\end{array}$ & $0.0 \%(n=0)$ & $0.0 \%(n=0)$ & $\begin{array}{l}25.8 \% \\
(n=80)\end{array}$ \\
\hline $\begin{array}{l}\text { Oral and } \\
\text { maxillofacial } \\
\text { pathology }\end{array}$ & $\begin{array}{l}75.0 \% \\
(n=3)\end{array}$ & $\begin{array}{l}75.0 \% \\
(n=3)\end{array}$ & $\begin{array}{l}52.9 \% \\
(n=18)\end{array}$ & $\begin{array}{l}25.0 \% \\
(n=1)\end{array}$ & $25.0 \%(n=1)$ & $\begin{array}{l}47.1 \% \\
(n=16)\end{array}$ \\
\hline $\begin{array}{l}\text { Oral } \\
\text { medicine* }\end{array}$ & $0.0 \%(n=0)$ & $\begin{array}{l}0.0 \% \\
(n=0)\end{array}$ & $\begin{array}{l}57.1 \% \\
(n=40)\end{array}$ & $\begin{array}{l}100.0 \% \\
(n=2)\end{array}$ & $100.0 \%(n=1)$ & $\begin{array}{l}42.9 \% \\
(n=30)\end{array}$ \\
\hline $\begin{array}{l}\text { Oral } \\
\text { microbiology }\end{array}$ & $\begin{array}{l}50.0 \% \\
(n=1)\end{array}$ & $\begin{array}{l}100.0 \% \\
(n=1)\end{array}$ & $\begin{array}{l}28.6 \% \\
(n=2)\end{array}$ & $\begin{array}{l}50.0 \% \\
(n=1)^{\star \star}\end{array}$ & $0.0 \%(n=0)$ & $\begin{array}{l}71.4 \% \\
(n=5)\end{array}$ \\
\hline Oral surgery & $\begin{array}{l}58.8 \% \\
(n=10)\end{array}$ & $\begin{array}{l}60.0 \% \\
(n=6)\end{array}$ & $\begin{array}{l}67.8 \% \\
(n=499)\end{array}$ & $\begin{array}{l}41.2 \% \\
(n=7)^{\star \star}\end{array}$ & $\begin{array}{l}40.0 \% \\
(n=4) \dagger\end{array}$ & $\begin{array}{l}32.2 \% \\
(n=237)\end{array}$ \\
\hline Orthodontics* & $\begin{array}{l}73.3 \% \\
(n=11)\end{array}$ & $\begin{array}{l}78.6 \% \\
(n=11)\end{array}$ & $\begin{array}{l}49.2 \% \\
(n=680)\end{array}$ & $\begin{array}{l}26.7 \% \\
(n=4)\end{array}$ & $21.4 \%(n=3)$ & $\begin{array}{l}50.8 \% \\
(n=703)\end{array}$ \\
\hline $\begin{array}{l}\text { Paediatric } \\
\text { dentistry }\end{array}$ & $\begin{array}{l}41.2 \% \\
(n=7)\end{array}$ & $\begin{array}{l}27.3 \% \\
(n=3)\end{array}$ & $\begin{array}{l}21.1 \% \\
(n=51)\end{array}$ & $\begin{array}{l}58.8 \% \\
(n=10)^{\star \star}\end{array}$ & $72.7 \%(n=8) \dagger$ & $\begin{array}{l}78.9 \% \\
(n=191)\end{array}$ \\
\hline Periodontics & $\begin{array}{l}89.5 \% \\
(n=17)\end{array}$ & $\begin{array}{l}87.5 \% \\
(n=14)\end{array}$ & $\begin{array}{l}67.2 \% \\
(n=260)\end{array}$ & $\begin{array}{l}10.5 \% \\
(n=2)\end{array}$ & $12.5 \%(n=2)$ & $\begin{array}{l}32.8 \% \\
(n=127)\end{array}$ \\
\hline Prosthodontics & $\begin{array}{l}76.5 \% \\
(n=13)\end{array}$ & $\begin{array}{l}81.8 \% \\
(n=9)\end{array}$ & $\begin{array}{l}76.5 \% \\
(n=342)\end{array}$ & $\begin{array}{l}23.5 \% \\
(n=4)\end{array}$ & $18.2 \%(n=2) \dagger$ & $\begin{array}{l}23.5 \% \\
(n=105)\end{array}$ \\
\hline $\begin{array}{l}\text { Restorative } \\
\text { dentistry }\end{array}$ & $\begin{array}{l}80.0 \% \\
(n=20)\end{array}$ & $\begin{array}{l}81.0 \% \\
(n=17)\end{array}$ & $\begin{array}{l}72.5 \% \\
(n=214)\end{array}$ & $\begin{array}{l}20.0 \% \\
(n=5)\end{array}$ & $19.0 \%(n=4) \dagger$ & $\begin{array}{l}27.5 \% \\
(n=81)\end{array}$ \\
\hline $\begin{array}{l}\text { Special care } \\
\text { dentistry }\end{array}$ & $\begin{array}{l}23.1 \% \\
(n=6)\end{array}$ & $\begin{array}{l}18.2 \% \\
(n=4)\end{array}$ & $\begin{array}{l}27.3 \% \\
(n=80)\end{array}$ & $\begin{array}{l}76.9 \% \\
(n=20)\end{array}$ & $\begin{array}{l}81.8 \% \\
(n=18) \dagger\end{array}$ & $\begin{array}{l}72.7 \% \\
(n=213)\end{array}$ \\
\hline \multicolumn{7}{|c|}{$\begin{array}{l}\text { Key: } \\
*=\text { conferences domains with data for only one year as detailed in Table } 2 . \\
* *=\text { acceptably balanced. } \\
\dagger=\text { gender balance of these domains' specialty speakers was within } 10 \% \text { variance of the gender balance of } \\
\text { the specialty. }\end{array}$} \\
\hline
\end{tabular}

A total of 14 conference domains and 25 individual conference programmes were, therefore, available for data extraction (Table $2)$.

\section{Gender balance}

In combining all the conference programmes available for analysis, data were extracted for 352 invited speakers; $39.8 \%(n=140)$ of speakers were identified as female and $60.2 \%$ $(\mathrm{n}=212)$ as male.

In approximately one-fifth $(21.4 \%, \mathrm{n}=3)$ of all conference domains in the two-year period, gender was acceptably balanced to pre-specified criteria of $40-60 \%$ female speakers. In a further
$21.4 \%(n=3)$, female speakers outnumbered male speakers. In the remaining $55.1 \%(\mathrm{n}=8)$, male speakers outnumbered female speakers (Table 3). There were no conferences with only female or male speakers.

The domains with the highest proportion of female speakers in the combined two-year period were oral medicine $(66.7 \%, \mathrm{n}=6)$ and special care dentistry $(61.9 \%, \mathrm{n}=26)$. The domains with the lowest proportion of female speakers were orthodontics $(19.0 \%, \mathrm{n}=4)$ and periodontics $(18.4 \%, \mathrm{n}=7)$.

When assessing the conference programmes for individual years, the mean number of female speakers was 5.4 (range 1-16) and of male 
Table 2 Availability of conference programme information by conference domain for 2018 and 2019

\begin{tabular}{l|l|l}
\hline Conference domain & 2018 speaker information & 2019 speaker information \\
\hline General dentistry & $\checkmark$ & $\checkmark$ \\
\hline Dental and maxillofacial radiology & $\checkmark$ & $\checkmark$ \\
\hline Dental public health & $\checkmark$ & $\checkmark$ \\
\hline Endodontics & X & $\checkmark$ \\
\hline Oral and maxillofacial pathology & $\checkmark$ & $\checkmark$ \\
\hline Oral medicine & $X^{* *}$ & $\checkmark$ \\
\hline Oral microbiology & $\checkmark^{*}(2016)$ & $\checkmark *(2018)$ \\
\hline Oral surgery & $\checkmark$ & $\checkmark$ \\
\hline Orthodontics & $\checkmark$ & X \\
\hline Paediatric dentistry & $\checkmark$ & $\checkmark$ \\
\hline Periodontics & $\checkmark$ & $\checkmark$ \\
\hline Prosthodontics & $\checkmark$ & $\checkmark$ \\
\hline Restorative dentistry & $\checkmark$ & $\checkmark$ \\
\hline $\begin{array}{l}\text { Special care dentistry } \\
\text { Key: } \\
* * \text { indicates that conference is held biennially; therefore, programmes for 2016 and 2018 analysed. } \\
* * \text { main scientific conference programme not available; therefore, excluded from analysis. }\end{array}$ \\
\hline
\end{tabular}

Table 3 The percentage of male and female speakers at each conference domain for combined events in 2018-2019. Gender was acceptably balanced to pre-specified criteria of $40-60 \%$ female speakers

\begin{tabular}{l|l|l|l}
\hline Conference domain & Male & Female & Gender balance \\
\hline General dentistry & $63.0 \%(n=17)$ & $37.0 \%(n=10)$ & Male \\
\hline Dental and maxillofacial radiology & $66.7 \%(n=8)$ & $33.3 \%(n=4)$ & Male \\
\hline Dental public health & $48.0 \%(n=12)$ & $52.0 \%(n=13)$ & Acceptably balanced \\
\hline Endodontics* & $60.0 \%(n=3)$ & $40.0 \%(n=2)$ & Acceptably balanced \\
\hline Oral and maxillofacial pathology & $66.7 \%(n=8)$ & $33.3 \%(n=4)$ & Male \\
\hline Oral medicine* & $33.3 \%(n=3)$ & $66.7 \%(n=6)$ & Female \\
\hline Oral microbiology & $39.4 \%(n=13)$ & $60.6 \%(n=20)$ & Female \\
\hline Oral surgery & $72.1 \%(n=31)$ & $27.9 \%(n=12)$ & Male \\
\hline Orthodontics* & $81.0 \%(n=17)$ & $19.0 \%(n=4)$ & Male \\
\hline Paediatric dentistry & $42.9 \%(n=15)$ & $57.1 \%(n=20)$ & Acceptably balanced \\
\hline Periodontics & $81.6 \%(n=31)$ & $18.4 \%(n=7)$ & Male \\
\hline Prosthodontics & $73.9 \%(n=17)$ & $26.1 \%(n=6)$ & Male \\
\hline Restorative dentistry & $77.8 \%(n=21)$ & $22.2 \%(n=6)$ & Male \\
\hline Special care dentistry & $38.1 \%(n=16)$ & $61.9 \%(n=26)$ & Female \\
\hline Keyarks conferences domains with a partial dataset as detailed in Table 2. & \\
\hline
\end{tabular}

speakers was 8.5 (range 3-17) per conference. The gender balance of speakers improved from 2018 to 2019 , with the overall proportion of female speakers per year increasing from $35.0 \%(n=64)$ to $45.0 \%(n=76)$, respectively.

\section{Length of presentation}

In combining all the conference programmes available for analysis, the mean length of presentation as advertised was 31 minutes (range 5-60 minutes) for female speakers compared to 40 minutes (range 5-120 minutes) for male speakers. The mean length of presentation for female speakers increased by four minutes from 29 minutes in 2018 to 33 minutes in 2019. However, the mean length of presentation for male speakers also increased by two minutes from 39 minutes to 41 minutes in the same period.

\section{Professional role}

A variety of professional roles were listed with speaker details including specialist dentists, speciality registrars, consultants, clinical academics, dental care professionals, medical professionals, speakers from allied sciences, medico-legal companies and those with recognised interests in wellbeing or leadership. In total, $11.1 \%(\mathrm{n}=39)$ of speakers were based internationally, hence are not GDC-registered and therefore were excluded from analysis of the secondary objective.

\section{Session chairs and panel members}

Details of session chairs and panel members were often missing or incomplete, with only $52.0 \%(\mathrm{n}=13)$ of conference programmes including this information and often only partially. However, where these data were available, the gender balance was improved compared to that of speakers, comprising $46.7 \%$ $(\mathrm{n}=28)$ females and $53.3 \%(\mathrm{n}=32)$ males.

\section{Comparison of gender balance of} speakers with GDC-registered dentists In total, $55.1 \%(\mathrm{n}=194)$ of all speakers were GDC-registered dentists, of which $41.2 \%$ $(\mathrm{n}=80)$ were female and $58.8 \%(\mathrm{n}=114)$ were male, therefore meeting the pre-specified criteria for acceptable gender balance. However, this balance is suboptimal in comparison to the actual gender distribution observed for GDCregistered dentists (Table 4).

Comparison of gender balance of specialist speakers with GDC specialist lists

In combining all the conference programmes available for analysis, $46.9 \%(\mathrm{n}=165)$ of all speakers were registered on the GDC specialist lists. The gender balance of specialist dentists for each speciality conference varied, as does the gender distribution within each speciality itself (Table 1$)$. At $38.5 \%(n=5)$ of speciality conferences, the proportion of female specialist speakers was $40-60 \%$. The mean number of female specialist speakers was 4.9 (range 0-20) and of male specialist speakers was 7.1 (range 0-20). 
There were two speciality conferences with exclusively female or male specialist speakers, which were endodontics and oral medicine. The speciality conferences with the highest proportions of female specialist speakers were oral medicine $(100.0 \%, \mathrm{n}=2)$ and dental public health $(75.0 \%, \mathrm{n}=8)$. The domains with the lowest proportions of female specialist speakers were periodontics $(10.5 \%, \mathrm{n}=3)$ and endodontics, which had no female specialist speakers in the partial dataset available for analysis.

When analysing the proportion of specialist female speakers registered with the relevant domain's speciality, 38.5\% $(\mathrm{n}=5)$ had a specialist speaker demographic that was within a $10 \%$ variance of the demographic of registered specialists. Specialties with a higher proportion of female registrants tended to have a higher proportion of female specialist speakers.

\section{Discussion}

This study presents the first descriptive analysis of gender balance for invited speakers at UK conferences of general and specialist dentistry. The findings support the shared call for action to increase gender equity across healthcare. ${ }^{29,30,31}$ The findings reflect those of similar studies of conferences in medicine. ${ }^{19,20,21,22,23}$ Also in line with these studies, there was an improvement in overall gender balance between the two years of conferences considered in this study. This finding is optimistic; however, in the absence of previous studies for dentistry, it should be interpreted with caution.

Implicit within gender balance, we do not seek to under-represent male speakers nor to misrepresent an individual speciality demographic. However, the findings of this study have demonstrated that a majority of dental conferences in the most recent two years have under-represented the female voice of our workforce, both from an empirical perspective and proportionally in relation to the demographics of their registrants. This is evident not only within the majority of individual dental specialties, but also within dentistry as a whole. The findings of this study are in line with those reported in the medical literature, where it has been reported that gender imbalance of invited speakers is compounded in specialties with proportionately fewer female registrants..$^{24,25}$

The methodological approach in previously reported studies of gender balance in conferences of medicine is variable. As in
Table 4 Gender balance of conference speakers and GDC-registered dentists

\begin{tabular}{l|l|l|l}
\hline Type & Female & Male & Gender balance \\
\hline $\begin{array}{l}\text { GDC-registered dentists } \\
\text { (registrants at March 2020) }\end{array}$ & $50.4 \%(n=21,003)$ & $49.6 \%(n=20,667)$ & Acceptably balanced \\
\hline $\begin{array}{l}\text { Conference speakers registered } \\
\text { as dentists with the GDC }\end{array}$ & $41.2 \%(n=80)$ & $58.8 \%(n=114)$ & Acceptably balanced \\
\hline
\end{tabular}

this study, gender is routinely determined by consideration of name, personal knowledge of the speaker or by searching in the public domain. ${ }^{19,20,21,23}$ One similar study utilised the GBAT. ${ }^{22}$ The GBAT enables automated evaluation of the probabilistic gender of names on a list, before providing an estimate of gender balance. The GBAT provides a convenient algorithm; however, given the relatively small size of conferences in dentistry, the method used in this study was considered to be more appropriate to accurately address the research question, despite being more time-consuming. Future research which seeks to analyse the gender balance of speakers in dentistry over a longer observed period, or with a larger dataset, may consider use of the GBAT.

Similar studies of conferences in medicine have reported that utilising 'first time' speakers, rather than 'repeat' speakers, may yield gender parity. ${ }^{20}$ It has also been suggested that speaker membership of conference host specialist societies may be relevant to gender balance. ${ }^{21}$ These factors were not explored within this study; however, this raises an interesting question with regards to gender balance of specialist society membership versus gender balance of the registered specialists themselves.

It has been previously reported that an increased representation of women on medical conference organising committees may have a positive impact on the gender balance of invited speakers. ${ }^{20,26,27,28}$ This finding was not considered within the scope of the present study; however, it could be considered an area of interest for future research if the identity of conference organising committee members is included within programme content. No similar studies within the medical literature included analysis of the mean length of presentation or the professional role of speakers, and few considered the gender balance of session chairs and panel members. The present study, therefore, provides a comparatively detailed review of conferences in dentistry from which recommendations can be made.

A fundamental recommendation arising from the findings of this study is that conference organising committees consider the content of their programmes as a source of imperative information for addressing gender equity within their domains, while also promoting the content. The inclusion of complete speaker details within accessible conference programmes will assist future researchers.

It is recognised that gender presents just one of many characteristics that should be balanced in the quest for equity. Retrospective analysis of age, disability and race of invited conference speakers would be complicated by the diverse approach to programme design. Dentists identifying as non-binary gender and women of additional visible minorities likely face further barriers that were not assessed in this study and further research is recommended. ${ }^{22}$ It is hoped that the findings of this study may inform future conference organising committees to proactively and prospectively strive towards more representative programmes for the entire profession. $^{20}$

Several specialties do not make their conference programmes available in the public domain and a number provided incomplete programmes. This prevented a complete analysis of the gender balance of invited speakers to these events. It is apparent that many conference organising committees have moved away from the mass production of printed programmes and towards paperless conferences, which allow the storing and long-term presentation of online programme content while also offering sustainability. Despite this, there is surprising variation in the amount of detail contained within conference programmes across dentistry. In particular, there was variation in the details published regarding session chairs and duration of presentations. There is much discussion across healthcare education regarding the presence of the 'manel' - an all-male panel. ${ }^{30}$ As many programmes do not clearly indicate which speakers belong to which sessions, it is difficult to analyse the presence of 'manels' at conferences in dentistry. However, it is reassuring that all conferences had female speakers. The public, online sharing of conference programmes may aid consistency, collaboration and future research in this area. 
Compiling conference programmes is a complex task. Assembling key speakers to fit the commands of a fixed schedule, the feedback of previous attendees, the learning needs of the target audience and the practicalities of travel and availability is no mean feat. Despite the recognition of these competing interests, it is nonsensical that gender should continue to impact conference programme assimilation if it is accepted that the profession strives away from inequity and disparity of opportunity. It is recognised that many will consider programme content a priority; however, indifference towards gender balance of speakers is at odds with the call for action to address diversity and inclusivity across healthcare. Addressing gender imbalance requires conference organisers, attendees and speakers to actively raise awareness and provide a platform for female speakers. ${ }^{17}$ Clear strategies are needed to counteract issues that may disproportionately affect female speakers and attendees, such as family-friendly conferences with baby-feeding and crèche facilities. ${ }^{31}$

Within dentistry, analysis of gender balance of specialist speakers within small specialties can be disproportionately affected by size. Notably, for dental and maxillofacial radiology and oral medicine, which are relatively small specialties, analysis in this study was necessarily based on the presence of a single female specialist speaker. Similarly, oral and maxillofacial pathology is a small speciality and was impacted by the effect of a small number of specialist speakers. However, it would be inappropriate to exclude these specialties based on their size and arguably irrelevant to the quest for gender balance.

Almost half of all invited speakers in this study were aligned with alternate specialities or professions than the conference at which they presented. Specialties with proportionately fewer female specialist registrants improved the overall gender parity of their conference programmes by inviting speakers from other dental specialties or beyond the dental profession. An opportunity therefore presents to specialties with proportionately fewer female specialists that they consider inviting female speakers from alternate fields - an acceptable approach in an era of multidisciplinary team working and learning from shared best practice. In doing so, perhaps the dental profession can begin to address the balances at play within the workforce itself.

Analysis of gender balance in this study relied upon binary gender data to describe the representation of speakers, in the same way as GDC registrants are required to annually selfreport as male or female. It is acknowledged that a degree of misgendering may occur in the public domain and therefore this presents a limitation of this study. Furthermore, it is recognised that gender may include biological sex, gender roles and gender identity. A binary approach to data interpretation in this study did, however, enable the inaugural descriptive analysis of gender balance in conferences of dentistry. Conferences of maxillofacial surgery and of dental care professionals were beyond the objectives of this study; however, their findings would be of interest with respect to similarity to general and specialist dental domains and gender balance of the workforce. This study considered the most recognised single conference representatives of general dentistry and of each dental speciality. Future researchers may seek to include multiple conferences in their analyses.

Conferences of the year 2020 were widely disrupted or deferred in light of the COVID19 pandemic. It is reported that the pandemic has exacerbated gender inequality with respect to global health and gender roles. ${ }^{34}$ Perhaps there is a silver lining in the commotion as education across healthcare remodels to enable hybrid teaching and as online formats rapidly replace face-to-face meetings. Consequently, conference organisers may consider how national events could adapt to the changes faced in the new normal. Efforts to collaborate and remove bureaucratic barriers are moving at unprecedented speed. Conceivably, speakers presenting online will no longer be restricted by the practicalities of travel and availability that once may have hampered their attendance and that may disproportionately affect women. Now, more than ever, is the time to advocate for wider societal gender and health equity goals.

\section{Conclusion}

Gender imbalance exists in speakers invited to present at recent conferences in dentistry. There is a call for further research to drive equity in the characteristics of invited speakers and to determine whether there is correlation with respect to representation in the composition of dental conference organising committees, to leadership and professional roles, and to the workforce. Conference organisers are encouraged to strive proactively and prospectively towards more representative programmes for the entire profession. Organising committees are encouraged to share best practice and the promotion of equity by providing publicly available, online programmes as a source of imperative information to encourage honest and transparent conversation for addressing the balance.

\section{Conflict of interest}

The authors have not identified any conflicts of interest.

\section{References}

1. World Health Organisation. Gender and health. 2020 Available at https://www.who.int/health-topics/gender (accessed May 2021).

2. Coen S, Banister E. What a difference sex and gender make: a gender, sex and health research casebook. Vancouver: CIHR Institute of Gender and Health, 2012.

3. Stonewall Youth. Gender identity. 2015. Available at https://www.youngstonewall.org.uk/lgbtq-info/ gender-identity (accessed May 2021).

4. Heidari S, Babor T F, Castro P, Tort S, Curno M. Sex and Gender Equity in Research: rationale for the SAGER guidelines and recommended use. Epidemio/ Serv Saude 2017; 26: 665-675.

5. The King's Fund. The Health Care Workforce in England: Make or Break? 2018. Available online at https://www. kingsfund.org.uk/publications/health-care-workforceengland (accessed May 2021).

6. World Health Organisation. Gender equity in the health workforce: Analysis of 104 countries. 2019. Available online at https://www.who.int/hrh/resources/gender equity-health_workforce_analysis/en/ (accessed May 2021)

7. The King's Fund. Women and medical leadership infographics. 2014. Available online at https://www. kingsfund.org.uk/audio-video/women-and-medicalleadership-infographics (accessed May 2021).

8. Sealy R. NHS Women on Boards 50:50 by 2020. 2017. Available online at https://www.nhsemployers.org/ case-studies-and-resources/2017/03/nhs-women-onboards-5050-by-2020 (accessed May 2021).

9. NHS Digital. Narrowing of NHS gender divide but men still the majority in senior roles. 2018. Available at https://digital.nhs.uk/news-and-events/latest-news/ narrowing-of-nhs-gender-divide-but-men-still-themajority-in-senior-roles (accessed May 2021).

10. Newman P. NHS women in leadership: Plan for action. 2015. Available at https://www.nhsemployers.org/-/ media/Employers/Publications/NHS-Women-inleadership_Br1322_WEB.pdf (accessed May 2021).

11. Rimmer A. Do we still need to tackle discrimination against women in medicine? BMJ 2017; DOI: 10.1136/ bmj.j1759.

12. Simpson R. Masculinity at work: the experiences of men in female dominated occupations. Work Employ Soc 2004; 18: 349-368.

13. England R, Stanfield J, Cliffe G. Striving for leadership in an unequal world. BDJ Team 2020; 7: 7-9.

14. Department of Health and Social Care. New data on gender pay gap in medicine. 2019. Available at https:// www.gov.uk/government/news/new-data-on-genderpay-gap-in-medicine (accessed May 2021).

15. Royal College of Surgeons of England. Women in Surgery. 2020. Available at https://www.rcseng.ac.uk/ careers-in-surgery/women-in-surgery/ (accessed May 2021)

16. Royal College of Surgeons of England. The Lady Estelle Wolfson Emerging Leaders Fellowship. 2020. Available at https://www.rcseng.ac.uk/careers-in-surgery/ women-in-surgery/the-lady-estelle-wolfson-emerging leaders-fellowship/ (accessed May 2021).

17. Penfold R, Knight K, Al-Hadithy N, Magee L, McLachlan $\mathrm{G}$. Women speakers in healthcare: speaking up for balanced gender representation. Future Healthc $J 2019$; 6: 167-171. 
18. Hoy K. Gender Imbalance at Brain Stimulation Conferences: We Have a Problem and It is Everyone's Problem. Brain Stimul 2017; 10: 155-156.

19. Dumitra T C, Trepanier M, Lee L et al. Gender distribution of speakers on panels at the Society of American Gastrointestinal and Endoscopic Surgeons (SAGES) annual meeting. Surg Endosc 2020; 34 4140-4147.

20. Kalejta R F, Palmenberg A C. Gender Parity Trends for Invited Speakers at Four Prominent Virology Conference Series. J Virol 2017; DOI: 10.1128/JVI.00739-17.

21. Gerull K M, Wahba B M, Goldin L M et al. Representation of women in speaking roles at surgical conferences. Am J Surg 2020; 220: 20-26.

22. Ruzycki S M, Fletcher S, Earp M, Bharwani A, Lithgow $K C$. Trends in the Proportion of Female Speakers at Medical Conferences in the United States and in Canada, 2007 to 2017. JAMA Netw Open 2019; DOI: 10.1001/jamanetworkopen.2019.2103.

23. Lorello G R, Parmar A, Flexman A M. Representation of women among speakers at the Canadian Anaesthesiologists' Society annual meeting: a retrospective analysis from 2007 to 2019. Can J Anaesth 2020; 67: 430-436.

24. Carley S, Carden R, Riley R et al. Are there too few women presenting at emergency medicine conferences? Emerg Med J 2016; 33: 681-683.

25. Larson A R, Sharkey K M, Poorman J A et al. Representation of Women Among Invited Speakers at Medical Speciality Conferences. J Womens Health (Larchmt) 2020; 29: 550-560.

26. Sardelis S, Drew J A. Not "Pulling up the Ladder": Women Who Organise Conference Symposia Provide Greater Opportunities for Women to Speak at Conservation Conferences. PLoS One 2016; DOI: 10.1371/journal.pone. 0160015 .

27. Rahimy E, Jagsi R, Park H S et al. Quality at the American Society for Radiation Oncology Annual Meeting: Gender Balance Among Invited Speakers and Associations with Panel Success. Int J Radiat Oncol Biol Phys 2019; 104: 987-996.

28. Lithgow K C, Earp M, Bharwani A, Fletcher S, Ruzycki S M. Association Between the Proportion of Women on a Conference Planning Committee and the Proportion of Women Speakers at Medical Conferences. JAMA Netw Open 2020; DOI: 10.1001/ jamanetworkopen.2020.0677.

29. The Lancet. Feminism is for everybody. Lancet 2019; 393: 493.

30. The Editors Of The Lancet Group. The Lancet Group's commitments to gender equity and diversity. Lancet 2019; 394: 452-453.

31. Lala R, Thompson W. 'An equal world is an enabled world': Equality in the dental profession. BDJ In Pract 2020; 33: 17-19.

32. NHS. Gender pay gap report: 2017/2018. 2019. Available online at https://www.england.nhs.uk/ publication/gender-pay-gap-report-2017-2018/ (accessed May 2021)

33. General Dental Council. Registration report - March 2020. 2020. Available at https://www.gdc-uk.org/docs/ default-source/registration-reports/registration-report--march-2020.pdf (accessed May 2021).

34. Wenham C, Smith J, Morgan R, Gender and COVID-19 Working Group. COVID-19: the gendered impacts of the outbreak. Lancet 2020; 395: 846-848. 